\title{
EPOXY COMPOSITES FILLED WITH NATURAL CALCIUM CARBONATE. 2. EPOXY COMPOSITES OBTAINED IN THE PRESENCE OF MONOMETHACRYLIC DERIVATIVE OF EPIDIAN-6 EPOXY RESIN
}

\author{
Michael Bratychak ${ }^{1,}$, Olena Astakhova1, Olena Shyshchak ${ }^{1}$, Maciej Sienkiewicz ${ }^{2}$, \\ Justyna Kucinska-Lipka ${ }^{2}$
}

https://doi.org/10.23939/chcht14.03.343

\begin{abstract}
On the basis of Epidian-6 epoxy resin and methacrylic acid a monomethacrylic derivative of Epidian6 with free epoxy and methacrylic groups (MMADER) has been synthesized. The structure of MMADER was confirmed by IR spectroscopy. The thermal stability of MMADER has been established. The cross-linking of unfilled epoxy-oligomeric mixtures and mixtures filled with $\mathrm{CaCO}_{3}$ has been studied in the presence of MMADER. By means of IR spectroscopy, the chemistry of the formation of mixtures based on Epidian-5, oligoesteracrylate TGM-3, MMADER and polyethylene polyamine has been established. Physico-mechanical characteristics of epoxy-oligomeric mixtures filled with $\mathrm{CaCO}_{3}$ have been established.
\end{abstract}

Keywords: epoxy resin, methacrylic acid, oligoesteracrylate, $\mathrm{CaCO}_{3}$, IR spectroscopy, structuring, physicomechanical properties, SEM.

\section{Introduction}

The production of composites with specified operational characteristics is one of the main tasks of modern polymer chemistry [1]. Nowadays the mostly used polymers for this purpose are epoxy resins [2-4]. They have a series of advantages compared with other polymers. Together with a hardener the epoxy resins are capable of forming the systems with low-viscosity allowing to produce irregular shaped products, the crosslinking of which may be carried out at both room and high temperatures. Such products are characterized by low shrinkage during hardening [3], they have high adhesion to hard surfaces, good dielectric properties, high resistance to aggressive environment, etc.

\footnotetext{
${ }^{1}$ Lviv Polytechnic National University

12, S.Bandery St., 79013 Lviv, Ukraine

${ }^{2}$ Gdansk University of Technology,

11/12 G. Narutowicza St., 80233 Gdansk, Poland

mbratychak@gmail.com

(c) Bratychak M., Astakhova O., Shyshchak O., Sienkiewicz M., Kucinska-Lipka, 2020
}

The introduction of filler into the epoxy resin based mixture increases the surface hardness, mechanical strength and thermal stability, as well as it reduces the price of the resulting product [3]. Among the known fillers there are graphite oxide [5], natural zeolite [6], $\mathrm{TiO}_{2}$ $[7,8]$ and others [9-13]. But $\mathrm{CaCO}_{3}$ is of special attention due to its availability [14-18].

Previously [19] we proposed to use $\mathrm{CaCO}_{3}$ when adding monoperoxide derivative of Epidian-6 (PO) to the epoxy-oligoesteric mixtures based on Epidian-5. PO contains epoxy group and $-\mathrm{O}-\mathrm{O}-$ bond in its structure allowing PO to be used as a compatibilizer and to bind all components of the mixture. The process was carried out first at room temperature for $24 \mathrm{~h}$, and then by heating to $423 \mathrm{~K}$ for $75 \mathrm{~min}$. The resulting products were characterized by high values of Young's modulus and Shore D hardness.

The aim of this work was to study Epidian- 5 based polymer mixtures which contain TGM-3 oligoesteracrylate as a plasticizer, $\mathrm{CaCO}_{3}$ as a filler, polyethylene polyamine (PEPA) as a curing agent and monomethacrylic derivative of Epidian-6 resin (MMADER) of the following formula as a compatibilizer.

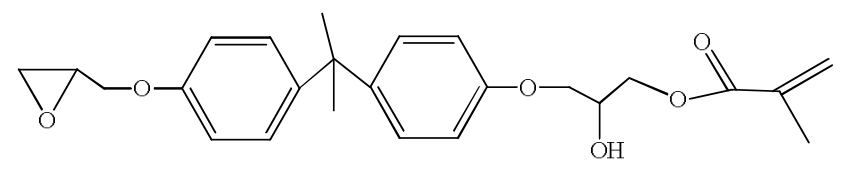

\section{Experimental}

\subsection{Materials}

The materials used for the experiments were:

Epidian-5 and Epidian-6 epoxy resins (SarzynaCiech, Poland) with a molecular weight $\left(M_{n}\right)$ of 390 and $340 \mathrm{~g} / \mathrm{mol}$, respectively, and epoxy groups content (e.n.) of 20.0 and $24 \%$, respectively. 
Methacrylic acid (MAA, Aldrich, South Korea) with $M_{n}$ of $86.09 \mathrm{~g} / \mathrm{mol}$ and density of $1 / 015 \mathrm{~g} / \mathrm{ml}$.

TGM-3 oligoesteracrylate (Ukraine) is an esterification product of methacrylic acid and triethylene glycol in the solvent medium with $M_{n} 286 \mathrm{~g} / \mathrm{mol}$.

Polyethylenepolyamine (PEPA, Ukraine) is the curing agent and was used as received without additional purification.

Tetrabutylammonium iodide $\left(\left[\mathrm{C}_{4} \mathrm{H}_{9}\right]_{4} \mathrm{NI}\right.$, TBAI, Aldrich) was used as a catalyst for the reaction of Epidian6 and MAA.

Calcium carbonate $\left(\mathrm{CaCO}_{3}\right.$, Sigma Aldrich) is a white odorless powder or colorless crystals.

\subsection{Methods of Analysis}

Molecular weight was determined by cryoscopy [20] using benzene as a solvent.

The epoxy groups content was determined according to the procedure described in [21], and bromine number - according to [22].

For IR spectroscopic investigations we used Specord-80 within a range of $4000-400 \mathrm{~cm}^{-1}$. The sample was prepared as a film formed from the oligomer solution in chloroform and applied on $\mathrm{KBr}$ plate; the film thickness was $0.03 \mathrm{~mm}$.

Thermographic investigations were carried out on Q1500 D derivatograph of Paulik-Paulik-Erdey system under dynamic mode in the air with a heating rate of $2.5 \mathrm{~K} / \mathrm{min}$. The samples with the weight of $300 \mathrm{mg}$ were heated to $523 \mathrm{~K}$. Alumina was a reference sample. The DTA sensitivity was $100 \mu \mathrm{V}$, TG sensitivity $-100 \mathrm{mg}$ and DTG sensitivity $-500 \mu \mathrm{V}$.

\subsection{Determination of Reaction Time for MMADER Synthesis}

The reaction was studied in a reactor equipped with a mechanical stirrer, thermometer, backflow condenser and tube for inert gas supply. Epidian-6, MMA and the solvent were loaded into the reactor and thermostated at $373 \mathrm{~K}$ under stirring. Then the TBAI catalyst $(5 \mathrm{~mol} \%$ relative to MMA) was added. The samples of $1 \mathrm{ml}$ were withdrawn over certain periods of time. The acid concentration was calculated according to Eq. (1)

$$
[C]_{\text {acid }}=\frac{N \cdot K \cdot V}{V_{s}}
$$

where $N$ is a normality of $\mathrm{KOH}$ solution, used for titration; $K$ is a correction factor for $0.1 \mathrm{~N} \mathrm{KOH} ; V$ is a $\mathrm{KOH}$ volume for titration, $\mathrm{ml} ; V_{s}$ is a sample volume $(1 \mathrm{ml})$.

\subsection{MMADER Synthesis}

MMADER was synthesized in a three-necked reactor equipped with a mechanical stirrer in the medium of inert gas. $50 \mathrm{~g}$ of Epidian- 6 dissolved in $125 \mathrm{ml}$ of toluene and $12.48 \mathrm{~g}$ of MAA were loaded into the reactor. The mixture was thermostated at $373 \mathrm{~K}$ under stirring and $2.68 \mathrm{~g}$ of the catalyst was added. The mixture was kept for $1.5 \mathrm{~h}$, cooled to the ambient temperature and placed in a separation funnel. The upper organic layer after separation was washed with distilled water till a neutral reaction and vacuumized so that $1 / 4$ of the solvent volume was distilled. The residue was precipitated with petroleum ether and dried at $313 \mathrm{~K}$ and residual pressure of 133-266 P till the constant weight. The resulting oligomer (MMADER) had $M_{n} 420 \mathrm{~g} / \mathrm{mol}$, e.n. $10.9 \%$ and bromine number $33.8 \mathrm{gBr}_{2} / 100$ g product.

\subsection{Preparation of Unfilled Epoxy- Oligomeric Mixtures}

Epoxy-oligomeric films were prepared by applying the mixture over glass standard plates. The mixture was prepared by mixing Epidian-5, MMADER, TGM-3 and PEPA. The mixture cross-linking was carried out stepwise: first at room temperature for $24 \mathrm{~h}$, then at $403 \mathrm{~K}$ for $15,30,45,60$ or $75 \mathrm{~min}$.

\subsection{IR Spectroscopic Investigations of Epoxy-Oligomeric Mixtures}

The investigations were carried out using Thermo Electron Corporation-Nicolet 8700 spectrophotometer with a Specac Golden Gate adapter and diamond ATR crystal. The samples were prepared as thin films applied over $\mathrm{KBr}$ plates. The experimental films were pressed by the plate with $\mathrm{KBr}$ using a mechanical device. The plates were placed in the desiccator, vaccumized and kept at room temperature for $24 \mathrm{~h}$. Then the samples were heated to 383 , 403 or $423 \mathrm{~K}$ for $30 \mathrm{~min}$ and IR spectra were recorded.

\subsection{Preparation of Epoxy Oligomeric Mixtures Filled with $\mathrm{CaCO}_{3}$}

Epidian-5, TGM-3, MMADER and $\mathrm{CaCO}_{3}$ were mixed till the homogeneous mixture was obtained. Then it was vacuumized to eliminate air bubbles. After PEPA addition the mixture was again mixed and vacuumized.

To determine the film hardness and gel-fraction content the samples were poured over the standard glass plates. To determine physico-mechanical properties the samples were poured into special moulds in the form of shovels and bars [19]. The shovels and bars were formed at room temperature for $24 \mathrm{~h}$. 


\subsection{Investigation Methods}

Films hardness ( $H$, rel.units) was determined according to the standard procedure [23] using M-3 pendulum device at room temperature. Gel-fraction content $(G, \%)$ was determined after extraction of grinded samples with acetone in Soxhlet apparatus for $12 \mathrm{~h} \mathrm{[23].}$

Tensile properties (ISO 527-21A), Charpy impact strength (ISO 179-1:2010), flexural properties (ISO 178:2010) and Shore D hardness (ISO 868) were determined with a Zwick/Roell device (Germany) in Gdansk University of Technology (Poland). Tensile tests were performed with a Zwick type Z020 tensile tester equipped with a $20 \mathrm{kN}$ load cell. The tests were performed on injection molded samples having the dimensions of $75 \times 4 \times 2 \mathrm{~mm}$. A grip-to-grip separation of $50 \mathrm{~mm}$ was used. The samples were pre-stressed to $3 \mathrm{~N}$ and then loaded with a constant cross-head speed of $50 \mathrm{~mm} / \mathrm{min}$. The average values reported were derived from at least five specimens.

SEM analysis of the freeze fractured samples were performed using HITACHI SU8010 apparatus equipped with a cold cathode field-emission source. The samples were sputter coated using a Cressington Sputter Coater 108Auto with Au.

\section{Results and Discussion}

\subsection{MMADER Obtaining, Characteristics and Properties}

\subsubsection{MMADER obtaining}

The synthesis of oligomers based on dianic epoxy resins with the unsaturated fragment and free epoxy group in their structure is of great interest from the standpoint of practical application. It means that this compound would be able to react via both polymerization and condensation mechanisms. A series of works $[24,25]$ describes a chemical modification of dianic epoxy resins by various unsaturated acids but with regard to the reactions, where epoxy groups are completely substituted for the fragments of unsaturated monobasic acid.

In this work we propose to obtain oligomers on the basis of Epidian-6 and methacrylic acid (Eq. (2)) which contain the free epoxy group and methacrylic fragment simultaneously. Tetrabutylammonium iodide (TBAI) is a catalyst. Toluene is a solvent which dissolves the initial reagents and the resulting product as well.

To determine the reaction time during which the half of epoxy groups is substituted for methacrylic fragments we used the procedure described in subsection 2.3. The experimental results are represented in Fig. 1.
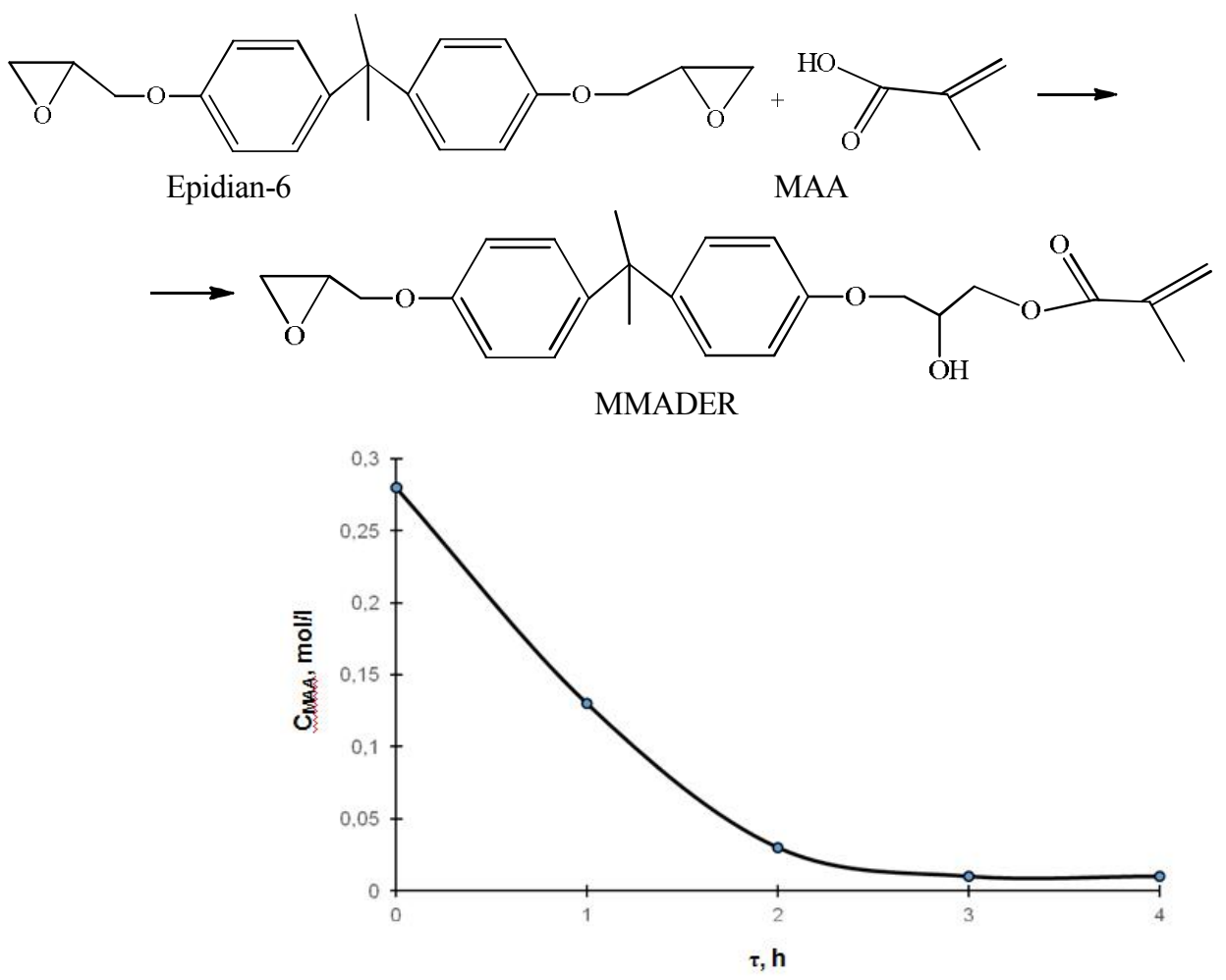

Fig. 1. MAA concentration $v s$. reaction time for the reaction of Epidian-6 and MAA at $373 \mathrm{~K}$ in the toluene medium. TBAI concentration is $5 \mathrm{~mol} \%$ relative to MAA. MAA content is $0.5 \mathrm{~mol}$ per $1 \mathrm{~g}$-eq of Epidian- 6 epoxy group 
Thus, the complete depletion of MAA concentration in the reaction medium is observed after 2-2.5 h. This fact allowed to develop the procedure for MMADER synthesis represented in subsection 2.4. According to the characteristics given in the mentioned Subsection, the synthesized MMADER simultaneously contains epoxy group and methacrylic fragment, the same as given in Eq. (2).

\subsubsection{IR spectroscopic investigations}

To confirm the MMADER structure we recorded its IR-spectrum (Fig. 2). The interpretation of the spectrum is given in Table 1. The data for Epidian-6 are given for the comparison.

One can see that MMADER contains epoxy groups, the same as Epidian-6. The absorption bands at 3056 and $912 \mathrm{~cm}^{-1}$ confirm this fact. However, unlike Epidian-6, the MMADER molecule contains MMA fragments (absorption bands at 1728,1636 and $1296 \mathrm{~cm}^{-1}$ ). The decrease in the intensity of band at $912 \mathrm{~cm}^{-1}$ and appearance of band at $3456 \mathrm{~cm}^{-1}$ indicate the opening of epoxy ring and formation of hydroxyl group due to the acid addition. The presence of $\left(\mathrm{CH}_{3}\right)_{2} \mathrm{C}$ - group in MMADER molecule is confirmed by a doublet of gel-methyl stretching vibrations at 1384 and $1360 \mathrm{~cm}^{-1}$, the presence of benzene rings - by absorption bands at 1456, 1504, 1580 and $1608 \mathrm{~cm}^{-1}$.

\subsubsection{Thermal stability of MMADER}

MMADER in the compositions may be used both at room temperature and at heating. Therefore, it is important to determine its thermal stability.

The procedure used is described in subsection 2.2 and the experimental results are represented in Fig. 3.

As can be seen from Fig. 3, the synthesized MMADER has a high thermal stability. A slight exoeffect on the DTA curve with the maximum at $568 \mathrm{~K}$ is accompanied with a mass loss within 550-593 K. The appearance of this effect may be explained by a partial thermodestruction of MMADER complicated by polymerization with respect to a double bond in the oligomer molecule.

\subsection{Cross-linking of Unfilled Epoxy- Oligomeric Mixtures}

Oligoesteracrylate TGM-3 as a plasticizer does not participate in the chemical formation of the product structure. It is capable of "sweating" during operational process that leads to the deterioration of the product properties. To eliminate this shortcoming it was proposed [19] to introduce a small amount of oligomer with free epoxy and peroxy groups to the mixture of industrial resin Epidian-5, TGM-3 and hardener PEPA. The peroxy group in the oligomer provides the binding of TGM-3 with the basic matrix. The synthesized MMADER contains the free epoxy group and methacrylic fragment allowing to use it for the creation of Epidian-5 based compositions.

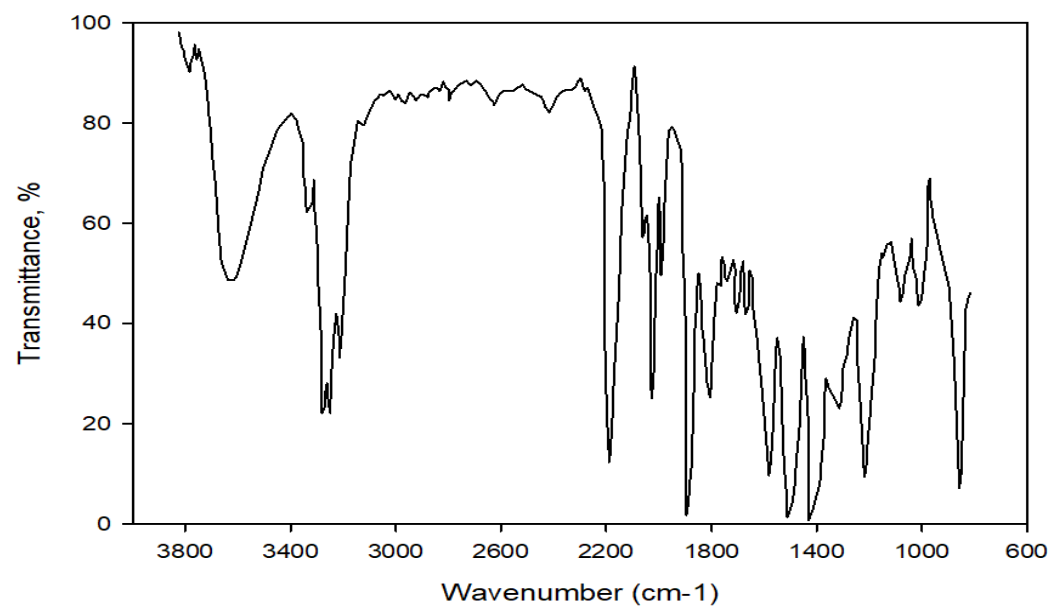

Fig. 2. IR spectrum of MMADER

Table 1

IR spectroscopic characteristics of oligomers

\begin{tabular}{|c|c|c|c|c|c|c|}
\hline \multirow{3}{*}{ Oligomer } & \multicolumn{6}{|c|}{ IR absorption bands, $\mathrm{cm}^{-1}$} \\
\hline & \multirow{2}{*}{$\begin{array}{c}-\mathrm{OH} \\
v_{\mathrm{OH}} \\
\end{array}$} & \multicolumn{2}{|c|}{7} & \multicolumn{3}{|c|}{$=\mathrm{C}-\mathrm{C} \geqslant{ }_{\mathrm{O}-\mathrm{C}}^{\mathrm{O}}$} \\
\hline & & $v_{\text {asCH2 }}$ & $v_{\mathrm{C}-\mathrm{O}-\mathrm{Cas}}$ & $v_{\mathrm{C}=\mathrm{O}}$ & $v_{\mathrm{C}=\mathrm{C}}$ & $v_{\mathrm{C}-\mathrm{O}-\mathrm{C}}$ \\
\hline Epidian-6 & - & 3050 & 910 & - & - & - \\
\hline MMADER & 3456 & 3056 & 912 & 1728 & 1636 & 1296 \\
\hline
\end{tabular}




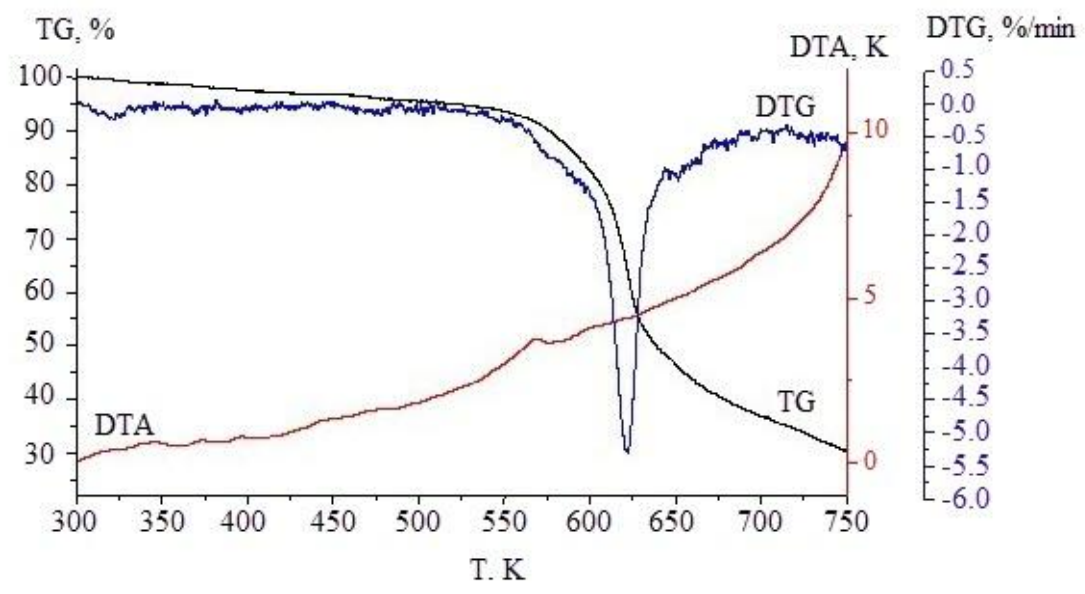

Fig. 3. Derivatographic curves for MMADER

Table 2

Composition of epoxy-oligomeric mixtures

\begin{tabular}{|c|c|c|}
\hline \multirow{2}{*}{ Component } & \multicolumn{2}{|c|}{ Components content, mass parts } \\
\cline { 2 - 3 } & I & II \\
\hline Epidian-6 & 80 & 20 \\
\hline MMADER & 20 & 10 \\
\hline TGM-3 & - & 14 \\
\hline PEPA & 14 & \\
\hline
\end{tabular}

Table 3

Dependence of gel-fraction content and polymer film hardness on cross-linking time and mixture composition at $403 \mathrm{~K}$

\begin{tabular}{|c|c|c|c|c|c|c|c|}
\hline \multirow{2}{*}{$\begin{array}{c}\text { Mixture number } \\
\text { according to Table 2 }\end{array}$} & \multirow{2}{*}{ Index } & \multicolumn{5}{|c|}{ Index value for cross-linking time, min } \\
\cline { 3 - 8 } & & $\begin{array}{c}24 \mathrm{~h}, \\
\text { normal conditions }\end{array}$ & 15 & 30 & 45 & 60 & 75 \\
\hline \multirow{2}{*}{ I } & $G$ & 84.7 & 94.5 & 95.7 & 95.9 & 95.9 & 95.9 \\
\hline \multirow{2}{*}{ II } & $H$ & 0.61 & 0.69 & 0.73 & 0.73 & 0.74 & 0.74 \\
\hline & $G$ & 87.9 & 92.0 & 92.3 & 92.5 & 92.6 & 93.3 \\
\cline { 2 - 8 } & $H$ & 0.55 & 0.72 & 0.74 & 0.74 & 0.74 & 0.74 \\
\hline
\end{tabular}

Notes: $G$ is a gel-fraction content, $\% ; H$ is a hardness determined by M-3 device, rel.units

\subsubsection{Gel-fraction content and hardness of polymer films}

Gel-fraction content and hardness of polymer films were determined according to the procedures described in subsection 2.5. The composition of epoxy-oligomeric mixtures and experimental results are represented in Tables 2 and 3, respectively.

So, the cross-linking of mixtures may occur at room temperature and at heating to $403 \mathrm{~K}$. When the film is formed at room temperature, the mixture without TGM-3 (mixture I, Table 2) has lower value of $G$ but a higher value of $H$ to compare with mixture II. The mixture I heating to $403 \mathrm{~K}$ for $15 \mathrm{~min}$ results in the sharp increase in a gel-fraction content and smooth increase in hardness. For mixture II we observe the sharp increase in film hardness which is not changed later. The gel-fraction content increases and remains virtually at the same level to the time of $75 \mathrm{~min}$. The obtained data can be explained based on the following considerations. At room temperature the three-dimensional structure is formed due to the reaction of epoxy groups of Epidian-5 and MMADER with PEPA molecules. At such interaction a heat is released and causes a partial cooligomerization 
with respect to double bonds of MMADER molecule (cross-linked with Epidian-5) and TGM-3 molecule (mixture II). This partial cooligomerization increases the gel-fraction content in mixture II compared with mixture I without TGM-3. Moreover, mixture II, which is crosslinked at room temperature, contains non cross-linked molecules of TGM-3 and thus the values of film hardness for mixture II are lower in comparison with mixture I. At $403 \mathrm{~K}$, already at the initial stage, the cooligomerization of TGM-3 molecules with partially cross-linked MMADER molecules continues. The increase in heating time does not significantly affect the gel-fraction content because TGM-3 molecules may be polymerized with each other but not cross-linked with the matrix molecules as it takes place in case with mixture I.

\subsubsection{IR spectroscopic investigations}

To determine the chemistry of the cross-linking process we carried out IR investigations for mixture II (Table 2). The structural changes were controlled by absorption bands at $920 \mathrm{~cm}^{-1}$ typical of asymmetric

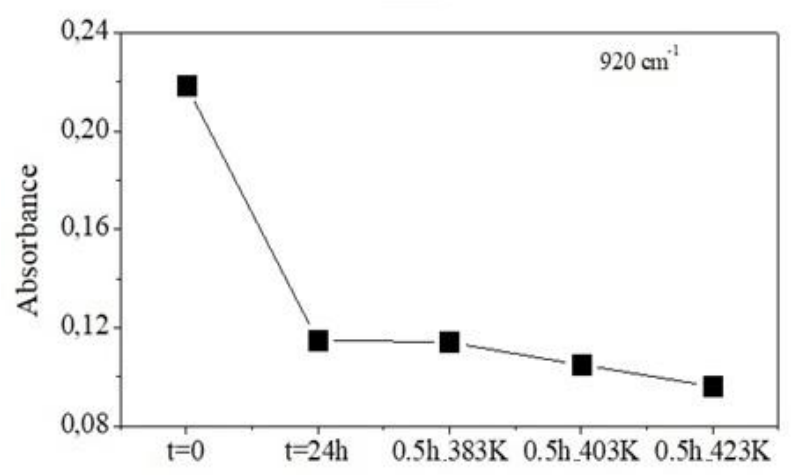

Fig. 4. Changes in the intensity of absorption band at $920 \mathrm{~cm}^{-1}$ after mixture preparation, keeping at room temperature for $24 \mathrm{~h}$ and after heating at 383, 403 and $423 \mathrm{~K}$ for $30 \mathrm{~min}$

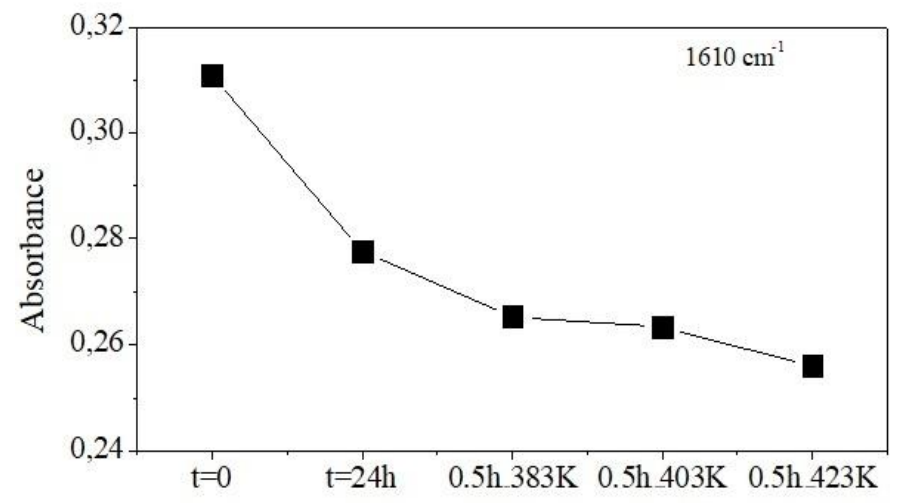

stretching vibrations of epoxy ring, at $1610 \mathrm{~cm}^{-1}$ typical of double bond and at $1720 \mathrm{~cm}^{-1}$ typical of carbonyl group.

It was found that spectra recorded after crosslinking at room temperature for $24 \mathrm{~h}$ differ from those recorded after heating (Fig. 4). The intensive absorption band at $920 \mathrm{~cm}^{-1}$ corresponding to the asymmetric stretching vibrations of epoxy ring in Epidian-5 and MMADER is observed for the initial mixture II. After keeping the mixture at room temperature for $24 \mathrm{~h}$ followed by heating, the band disappears. It means that epoxy groups of Epidian-5 and MMADER react with PEPA molecules.

The results represented in Figs. 5 and 6 show the role of TGM-3 and MMADER molecules in the crosslinking process. The partial polymerization with respect to double bonds for both TGM-3 and MMADER molecules occurs already at room temperature due to the heat release accompanied by the reaction of epoxy groups and PEPA. This is verified by the decrease of band intensity at $1720 \mathrm{~cm}^{-1}$ (Fig. 5) corresponding to the stretching vibrations of carbonyl group in unsaturated acid esters and band at $1610 \mathrm{~cm}^{-1}$ (Fig. 6) corresponding to double bonds.

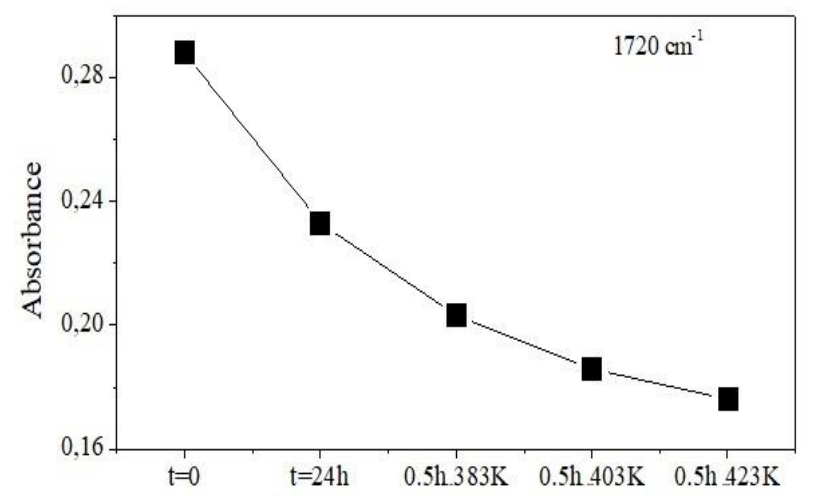

Fig. 5. Changes in the intensity of absorption band at $1720 \mathrm{~cm}^{-1}$ after mixture preparation, keeping at room temperature for $24 \mathrm{~h}$ and after heating at 383,403 and $423 \mathrm{~K}$ for $30 \mathrm{~min}$

Fig. 6. Changes in the intensity of absorption band at $1610 \mathrm{~cm}^{-1}$ after mixture preparation, keeping at room temperature for $24 \mathrm{~h}$ and after heating at 383,403 and $423 \mathrm{~K}$ for $30 \mathrm{~min}$ 
The obtained results confirm the participation of all components of mixture II in the film-forming process. At room temperature the initial Epidian-5 and MMADER in the presence of PEPA form a structure, in which MMADER molecule is grafted to the Epidian-5 based matrix. Due to the exothermal reaction of epoxide molecules and PEPA the partial polymerization between MMADER grafted molecule and TGM-3 takes place followed by the formation of additional amount of insoluble products. The mixture heating results in a continued interaction between functional groups of mixture II and formation of insoluble products.

\subsection{Cross-linking of Filled Epoxy- Oligomeric Mixtures}

The mixtures based on epoxy resins and filled with various mineral compounds improve the operational properties of the products on their basis [2] and reduces their cost [3]. However, TGM-3, which is present in some mixtures as a plasticizer, deteriorates the operational properties. The reason is TGM-3 inability to be chemically bound with the molecules of epoxy resin.

Previously [19] we proposed to use monoperoxy derivative of Epidian-6 resin to bind TGM-3 with Epidian-5 molecules. This oligomer contains free epoxy and peroxy groups allowing it to be a bonding agent for TGM-3 and Epidian-5 cross-linked by PEPA. TGM-3 molecules are attached to the Epidian- 5 based cross-linked matrix at heating due to the decomposition of peroxy group in the monoperoxy derivative and formation of free radicals generating a grafted polymerization.

Monomethacrylic derivative of Epidian-6 (MMADER) with the free epoxy group and methacrylic fragment in its structure may be a bonding agent for TGM-3 and Epidian-5 already at room temperature (Table 3 ). This fact allows to prepare mixtures filled with $\mathrm{CaCO}_{3}$ without additional heating.

The preparation and investigation of filled mixtures were carried out according to the procedure described in subsection 2.7. The composition of investigated mixtures is given in Table 4.

\subsubsection{Gel-fraction content and hardness of filled polymer films}

The gel-fraction content and hardness of the films filled with $\mathrm{CaCO}_{3}$ (vide Table 4) were studied using the procedure described in subsection 2.7 which consists of components mixing, PEPA addition, applying over the glass plates and keeping at room temperature for $24 \mathrm{~h}$. Some obtained results are given in Table 5.

If we compare mixtures without $\mathrm{CaCO}_{3}$ (mixtures 1 and 3, Table 4), we observe the slight increase in gelfraction content and significant increase in hardness due to the introduction of 10 mass parts of MMADER (mixture 3 ). This confirms the above stated results (subsection 3.2.1) about the role of MMADER for the formation of polymer films. The increase in gel-fraction content may be also achieved by introduction of 30 mass parts of $\mathrm{CaCO}_{3}$ into the mixture (mixture 2), however the hardness is low compared with mixture $\mathbf{1}$ and does not exceed 0.44 rel.units. The considerable increase in gel-fraction content and hardness was observed for mixture 4, containing $\mathrm{CaCO}_{3}$ and the synthesized MMADER. The values of hardness and gel-fraction content for the mixture 4 based films are 0.60 rel.units and $86.2 \%$, respectively, that is sufficient for the product to be used.

Table 4

Composition of the mixtures

\begin{tabular}{|c|c|c|c|c|c|c|c|}
\hline \multirow{2}{*}{ Component } & \multicolumn{7}{|c|}{ Components content, mass parts } \\
\cline { 2 - 9 } & $\mathbf{1}$ & $\mathbf{2}$ & $\mathbf{3}$ & $\mathbf{4}$ & $\mathbf{5}$ & $\mathbf{6}$ & $\mathbf{7}$ \\
\hline Epidian-5 & 100 & 100 & 90 & 90 & 90 & 90 & 95 \\
\hline MMADER & 0 & 0 & 10 & 10 & 10 & 10 & 5 \\
\hline TGM-3 & 10 & 10 & 10 & 10 & 10 & 10 & 10 \\
\hline PEPA & 14 & 14 & 13.5 & 13.5 & 13.5 & 13.5 & 13.5 \\
\hline $\mathrm{CaCO}_{3}$ & 0 & 30 & 0 & 30 & 60 & 10 & 30 \\
\hline
\end{tabular}

Table 5

Gel-fraction content and hardness of polymer films

\begin{tabular}{|c|c|c|}
\hline Mixture number according to Table 4 & Gel-fraction content, \% & Hardness, rel. units \\
\hline $\mathbf{1}$ & 82.2 & 0.40 \\
\hline $\mathbf{2}$ & 87.4 & 0.44 \\
\hline $\mathbf{3}$ & 84.0 & 0.62 \\
\hline $\mathbf{4}$ & 86.2 & 0.60 \\
\hline
\end{tabular}


Physico-mechanical properties of the mixtures

\begin{tabular}{|c|c|c|c|c|c|c|c|}
\hline \multirow{2}{*}{$\begin{array}{c}\text { Mixture } \\
\text { number } \\
\text { according to } \\
\text { Table 4 }\end{array}$} & $T S_{b}, \mathrm{mPa}$ & $E_{b}, \%$ & $E_{\text {Mod }}, \mathrm{GPa}$ & $\begin{array}{c}\text { Charpy } \\
\text { impact } \\
\text { strength, } \\
\end{array}$ & & & \multicolumn{2}{|c|}{ Tensile tests } & $F_{\text {max }}, \mathrm{N} / \mathrm{mm}^{2}$ & e-break, \% & \multirow{2}{*}{$\begin{array}{c}\text { Shore D } \\
\text { hardness }\end{array}$} \\
\hline $\mathbf{1}$ & 46.2 & 1.96 & 3.22 & 1.59 & 87.62 & 3.23 & 79.7 \\
\hline $\mathbf{2}$ & 15.7 & 0.83 & 2.40 & 1.95 & 26.05 & 1.08 & 78.5 \\
\hline $\mathbf{3}$ & 35.4 & 1.55 & 2.64 & 5.76 & 88.17 & 3.45 & 78.5 \\
\hline $\mathbf{4}$ & 25.2 & 1.26 & 3.36 & 2.77 & 31.15 & 1.14 & 78.1 \\
\hline $\mathbf{5}$ & 21.2 & 0.60 & 3.81 & 2.62 & 35.06 & 0.92 & 81.5 \\
\hline $\mathbf{6}$ & 30.6 & 1.60 & 2.35 & 2.37 & 43.54 & 1.75 & 78.6 \\
\hline $\mathbf{7}$ & 20.6 & 1.24 & 2.40 & 1.80 & 32.48 & 1.26 & 83.3 \\
\hline
\end{tabular}

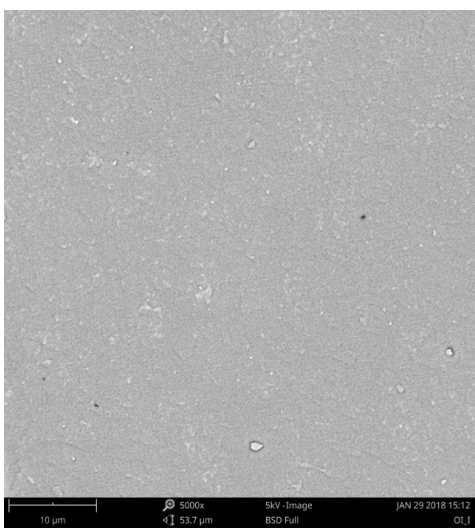

a)

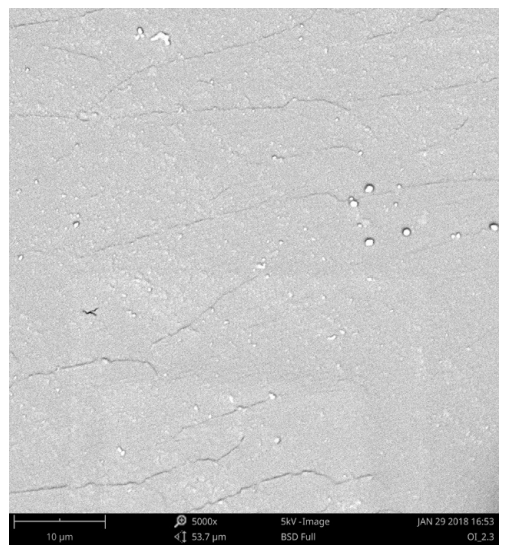

c)

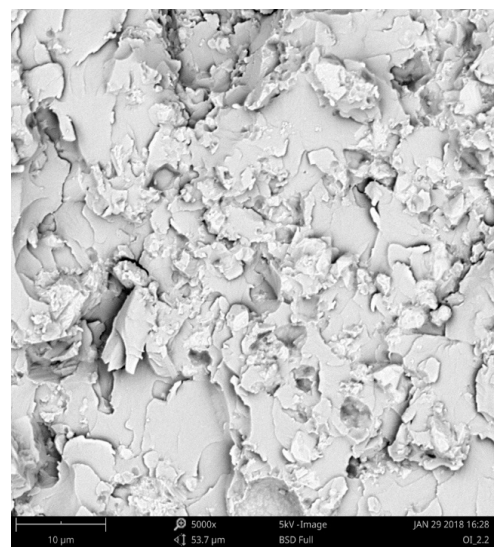

b)

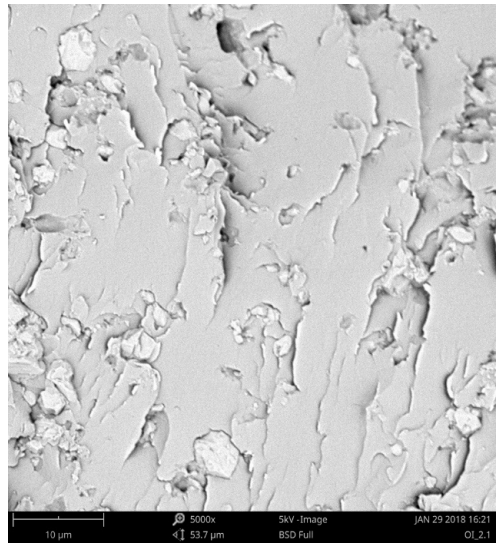

d)

Fig. 7. SEM images of mixture 1 (a), mixture 2 (b), mixture 3 (c) and mixture 4 (d)

\subsubsection{Physico-mechanical properties}

Physico-mechanical properties of the mixtures were studied according to the procedure described in subsection 2.7. The experimental results are given in Table 6.

The comparison of mixtures without MMADER (mixtures 1 and 2) show that the introduction of $\mathrm{CaCO}_{3}$ decreases the values of maximum tensile strength $\left(T S_{b}\right)$, elongation at break $\left(E_{b}\right)$, maximum flexural strength $\left(F_{\max }\right)$, break deformation (e-break) and Young's modulus $\left(E_{M o d}\right)$ but slightly increases Charpy impact strength. The value of Shore $\mathrm{D}$ hardness varies insignificantly. It means that introduction of $\mathrm{CaCO}_{3}$ into the mixture slightly increases the hardness but makes the product brittle. Similar results were obtained when 10 mass parts of 
MMADER were introduced into the composition (mixture 3). The minor difference in values means the participation of MMADER in the product formation. The simultaneous introduction of MMADER and $\mathrm{CaCO}_{3}$ (mixture 4) decreases maximum tensile strength, maximum flexural strength and break deformation but increases Charpy impact strength. The increase in $\mathrm{CaCO}_{3}$ amount from 30 mass parts (mixture 4) to 60 mass part (mixture 5) at the same amount of MMADER (10 mass parts) decreases the value of $E_{b}$ almost twice but increases the values of $E_{\text {Mod }}$, $F_{\max }$ and Shore $\mathrm{D}$ hardness. The decrease in $\mathrm{CaCO}_{3}$ amount to 10 mass parts (mixture 6) increases the values of $T S_{b}, E_{b}, F_{\max }$ and e-break, decreases $E_{M o d}$ and impact strength but does not affect Shore D hardness (cf. mixture 4). If the amount of $\mathrm{CaCO}_{3}$ remains constant but the amount of MMADER decreases from 10 to 5 mass parts (mixture 7), we observe the increase in Shore D hardness. The rest values decrease.

On the whole, the introduction of MMADER into the mixture has a positive effect on physico-mechanical properties of the mixtures filled with $\mathrm{CaCO}_{3}$. SEM analysis (Fig. 7) shows that introduction of MMADER (Fig. 7c) practically does not affect the product morphology (cf. Fig. 7a). The presence of $\mathrm{CaCO}_{3}$ increases the product porosity (Fig. 7b). Simultaneous introduction of MMADER and $\mathrm{CaCO}_{3}$ decreases the porosity (Fig. 7d), which indicates the participation of MMADER molecules in the formation of product structure.

\section{Conclusions}

Monomethacrylic derivative of epoxy resin (MMADER) has been synthesized via reaction of Epidian6 epoxy resin and methacrylic acid. The synthesized product contains the free epoxy group and methacrylic fragment. It was determined that a half of epoxy groups in Epidian-6 resin is substituted at $373 \mathrm{~K}$ for $2-2.5 \mathrm{~h}$. The presence of free epoxy groups in the resulting product was confirmed by absorption bands at $912 \mathrm{~cm}^{-1}$ and methacrylic fragment - at 1728, 1636 and $1296 \mathrm{~cm}^{-1}$. Using derivatography the high thermal stability of MMADER was established.

The cross-linking of mixtures composed of Epidian-5 industrial resin, TGM-3 oligoesteracrylate, MMADER and PEPA as a hardener was studied. The values of gelfraction content and hardness were found to be $87.9 \%$ and 0.55 rel.units for the films cross-linked at room temperature for $24 \mathrm{~h}$. When the mixture was heated to
$403 \mathrm{~K}$ for $75 \mathrm{~min}$ the above values were $93.3 \%$ and 0.74 rel.units, respectively. IR investigations verified the participation of Epidian-5 and MMADER epoxy groups, as well as unsaturated methacrylic groups of MMADER and TGM-3 oligoesteracrylate in the cross-linking process. It was established that simultaneous introduction of the synthesized MMADER and $\mathrm{CaCO}_{3}$ into the mentioned mixtures significantly increases both the gel-fraction content and film hardness.

Physico-mechanical properties of the samples formed on the basis of epoxy-oligoesteric mixtures have been investigated. The effect of $\mathrm{CaCO}_{3}$ and MMADER amounts on the properties of polymeric products was studied. The morphology of the resulting products was determined using SEM analysis.

\section{References}

[1] Nielsen L., Landel R.: Mechanical Properties of Polymers and Composites, $2^{\text {nd }}$ edn. CRC Press, Boca Raton 1993.

[2] Chernin Ch., Smekhov F., Zherdeev Yu.: Epoksidnye Polymery i Kompozitsii. Khimia, Moskva 1982.

[3] Ellis B.: Chemistry and Technology of Epoxy Resins. Blackie Academic and Professional, London 1993.

[4] Hetmanchuk Yu., Bratychak M.: Khimiya i Technologiya Oligomeriv. Vyd-vo Kyiv Univ., Kyiv 2008.

[5] Tang L.-C., Wan Y.-J., Yan D et al.: Carbon, 2013, 60, 16. https://doi.org/10.1016/j.carbon.2013.03.050

[6] Lee J.-Y., Shim M.-J., Kim S.-W.: Mater. Chem. Phys., 1997, 48, 36. https://doi.org/10.1016/S0254-0584(97)80073-9

[7] Ng C., Ash B., Schadler L. et al.: Adv. Compos. Lett., 2001, 10, 101. https://doi.org/10.1177/096369350101000301

[8] Ng C., Schadler L., Siegel R.: Nanostruct. Mater., 1999, $12,507$. https://doi.org/10.1016/S0965-9773(99)00170-1

[9] Tee D., Mariatti M., Azizan A. et al.: Compos. Sci. Technol., 2007, 67, 2584. https://doi.org/10.1016/j.compscitech.2006.12.007

[10] Shi G., Zhang M.-Q., Rong M.-Z. et al.: Wear, 2003, 254, 784. https://doi.org/10.1016/S0043-1648(03)00190-X

[11] Schueler R., Petermann J., Schulte K. et al.: J. Appl. Polym. Sci., 1997, 63, 1741. https://doi.org/10.1002/(SICI)1097-

4628(19970328)63:13<1741::AID-APP5>3.0.CO;2-G

[12] Mohan T., Kanny K.: Compos. Part A-Appl. S., 2011, 42, 385. https://doi.org/10.1016/j.compositesa.2010.12.010

[13] Yung K., Zhu B., Yue T. et al.: Compos. Sci. Technol., 2009, 69, 260. https://doi.org/10.1016/j.compscitech.2008.10.014

[14] Leong Y., Abu Bakar M., Mohd Oshak Z. et al.: J. Appl.

Polym. Sci., 2004, 91, 3315. https://doi.org/10.1002/app.13542

[15] Shi Q., Wang L., Yu H. et al.: Macromol. Mater. Eng., 2006,

291, 53. https://doi.org/10.1002/mame.200500223

[16] Mustata F., Tudirachi N., Rosu D.: Compos. Part B-Eng., 2012, 43, 702. https://doi.org/10.1016/j.compositesb.2011.11.047

[17] Yu H., Wang L., Shi Q. et al.: Prog. Org. Coat., 2006, 55, 296. https://doi.org/10.1016/j.porgcoat.2006.01.007 
[18] He H., Li K., Wang J. et al.: Mater. Design, 2011, 32, 4521. https://doi.org/10.1016/j.matdes.2011.03.026

[19] Bratychak M., Astakhova O., Shyshchak O. et al.: Chem. Chem. Technol., 2019, 13, 360.

https://doi.org/10.23939/chcht13.03.360

[20] Odabiashian G., Shvets V.: Laboratornyi Praktikum po Khimii i Technologii Organicheskogo Sinteza. Khimia, Moskva 1982.

[21] Sorokin M., Lialiushko K.: Praktikum po Khimii i Technologii Plenkoobrazuyushikh Veshestv. Khimia, Moskva 1971.

[22] Siggia S.: Quantitative Organic Analysis via Functional Groups. Wiley 1979.

[23] Ivanov V.: Rukovodstvo k Prakticheskim Rabotam po Khimii Polimerov. Izd-vo Leningrad. Univ., Leningrad 1982.

[24] Bashta B., Astakhova O., Shyshchak O., Bratychak M..: Chem. Chem. Technol., 2014, 8, 309.

https://doi.org/10.23939/chcht08.03.309

[25] Bratychak M., Shyshchak O., Astakhova O., Ivashkiv O.:

Oligomers with Functional Groups Based on Epoxy Resins.

Synthesis, Properties and Application. Lviv Polytechnic Publ.

House, Lviv 2019.

Received: May 13, 2019/Revised: May 21, 2019 / Accepted: July 15, 2019

\section{ЕПОКСИДНІ КОМПОЗИТИ 3 НАТУРАЛЬНИМ \\ НАПОВНЮВАЧЕМ КАРБОНАТОМ КАЛЬЦІЮ. \\ 2. ОДЕРЖАННЯ ЕПОКСИДНИХ КОМПОЗИТІВ У ПРИСУТНОСТІ МОНОМЕТАКРИЛОВОӤ ПОХІДНОЇ ЕПОКСИДНОЇ СМОЛИ ЕРІDIAN-6}

\begin{abstract}
Анотація. На основі епоксидної смоли Epidian-6 $i$ метакрилової кислоти синтезована монометакрилова похідна епоксидної смоли Epidian-6, яка містить вільну епоксидну та метакрилову групу (ММАПЕС). Підтверджено структуру ММАПЕС з використанням ІЧ-спектроскопії. Встановлена термічна стабільність ММАПЕС. Вивчено структурування ненаповнених та наповнених $\mathrm{CaCO}_{3}$ епокси-олігомерних сумімей в присутності ММАПЕС. 3 використанням ІЧ-спектроскопії встановлено хімізм формування сумішей на основі Epidian-5, олігоестеракрилату ТГМ-3, ММАПЕС і поліетиленполіаміну. Встановлені фізико-механічні характеристики наповнених $\mathrm{CaCO}_{3}$ епокси-олігомерних сумішей.
\end{abstract}

Ключові слова: епоксидна смола, метакрилова кислота, олігоестеракрилат, $\mathrm{CaCO}_{3}$, ІЧ-спектроскопія, структурування, фізико-механічні властивості, СЕМ. 